\title{
Asymmetric indenothiophene-based non-fullerene acceptors for efficient polymer solar cells
}

\author{
Changquan Tang ${ }^{1,2 \dagger}$, Shan-Ci Chen ${ }^{1 \dagger}$, Qi Shang ${ }^{1}$ and Qingdong Zheng ${ }^{1 *}$
}

\begin{abstract}
Three new asymmetric acceptor-donor-acceptor structured molecules are designed and synthesized by incorporating indenothiophene as the central core. Their bandgaps and energy levels can be easily tuned by varying the electron withdrawing ability of the terminal groups such as dicyanovinyl, 3-ethylrhodanine, and 2-(1,1-dicyanomethylene)-3-ethyl-rhodanine. Inverted polymer solar cells using these molecules as acceptors and PTB7-Th as a donor material afford a highest power conversion efficiency of $7.49 \%$ with a high open circuit voltage of $1.02 \mathrm{~V}$ as well as a low energy loss of $0.59 \mathrm{eV}$.
\end{abstract}

Keywords: indenothiophene, non-fullerene acceptor, organic solar cell, power conversion efficiency, asymmetric

\section{INTRODUCTION}

Since the introduction of bulk heterojunction (BHJ) concept to the field of organic photovoltaics (OPV) [1], fullerenes and their derivatives such as $[6,6]-$ phenyl- $\mathrm{C}_{61}{ }^{-}$ butyric acid methyl ester $\left(\mathrm{PC}_{61} \mathrm{BM}\right)$ and $[6,6]$-phenyl- $\mathrm{C}_{71^{-}}-$ butyric acid methyl ester $\left(\mathrm{PC}_{71} \mathrm{BM}\right)$ have been chosen as the standard electron acceptor materials for $\mathrm{BHJ}$ organic solar cells (OSCs), owing to their excellent characteristics including high electron affinity, high electron mobility, isotropic charge transport property, and the ability to form favorable nanoscale morphological networks with donor materials [2,3]. However, fullerene-based acceptors have some intrinsic drawbacks, such as weak absorption in the visible region, limited tunability of energy levels, poor morphological stability in thin film blends over time, and relatively high synthetic costs. Thus, increasing attention has lately been paid on the development of non-fullerene acceptors (NFAs) that can be used to overcome the limitations of traditional fullerene acceptors [4-8]. To date, most of the successful NFAs are derived from strong electron deficient units, such as aromatic diimides (perylene diimides, naphthalene diimides, etc.) [9-17], dicyanovinyl [18-20], diketopyrrolopyrrole [21,22], and benzothiadiazole $[23,24]$. Among them, rod-like acceptordonor-acceptor (A-D-A) structured molecules in which an electron-rich fused-ring core is used as a central donor and two strong electron-withdrawing groups are used as acceptors, are promising for high performance OSCs because their optical and electronic properties can be easily tuned by varying the fused-ring core or the terminal groups, in comparison with those of fullerene-based electron acceptors or aromatic diimide-based NFAs [2533]. Although the non-fullerene OSCs have achieved a power conversion efficiency (PCE) up to $12 \%$ [26], the variety of high performance NFAs is still finite. Most high performance NFAs are based on a handful of fused-ring donor units such as indacenodithiophene (IDT) or indacenodithieno[3,2-b]thiophene [5-8]. Therefore, the search for novel NFAs based on unexplored building blocks is still urgently needed.

Previously, we reported an asymmetric donor unit, named indenothiophene, which was used for building $\mathrm{p}$ type semiconducting D-A copolymers for the first time $[34,35]$. The OSCs based on these asymmetric copolymers exhibited a high PCE up to $9.14 \%$ with a large open circuit voltage $\left(V_{\mathrm{OC}}\right)$ of $0.903 \mathrm{~V}$. These previous results suggest that the indenothiophene may also be an excellent donor unit for building efficient n-type A-D-A structured NFAs.

Here, we report three new asymmetric A-D-A structured NFAs, 2-((7-(5-(2-(7-(2,2-dicyanovinyl)benzo[c] $[1,2,5]$ thiadiazol-4-yl)-4,4-dioctyl-4H-indeno[1,2-b]thiophen-6-yl)thiophen-2-yl)benzo[c] [1,2,5] thiadiazol-4-yl) methylene)malononitrile (ITBC), (Z)-3-ethyl-5-((7-(5-(2-

\footnotetext{
${ }^{1}$ State Key Laboratory of Structural Chemistry, Fujian Institute of Research on the Structure of Matter, Chinese Academy of Sciences, Fuzhou 350002, China

${ }^{2}$ University of Chinese Academy of Sciences, Beijing 100049, China

These authors contributed equally to this paper.

"Corresponding author (email: qingdongzheng@fjirsm.ac.cn)
} 
(7-((Z)-(3-ethyl-4-oxo-2-thioxothiazolidin-5-ylidene)methyl)benzo[c] [1,2,5] thiadiazol-4-yl)-4,4-dioctyl-4H-indeno[1,2-b]thiophen-6-yl)thiophen-2-yl)benzo[c] $[1,2,5]$ thiadiazol-4-yl)methylene)-2-thioxothiazolidin-4-one (ITBR), and 2-((Z)-5-((7-(5-(2--(7-((Z)-(2-(dicyanomethylene)-3-ethyl-4-oxothiazolidin-5-ylidene)methyl) benzo[c] [1,2,5] thiadiazol-4-yl)-4,4-dioctyl-4H-indeno [1,2-b]thiophen-6-yl)thiophen-2-yl)benzo[c] [1,2,5]thiadiazol-4-yl)methylene)-3-ethyl-4-oxothiazolidin-2-ylidene)malononitrile (ITBRC), which were constructed by using the indenothiophene as electron donor core, benzothiadiazole (BT) as $\pi$ bridge, and dicyanovinyl, 3ethylrhodanine, 2-(1,1-dicyanomethylene)-3-ethylrhodanine as the electron withdrawing terminal groups, respectively (Chart 1). Using poly[4,8-bis(5-(2-ethylhexyl) thiophen-2-yl)benzo[1,2-b;4,5-b'] dithiophene-2,6-diylalt-(4-(2-ethylhexyl)-3-fluorothieno[3,4-b]thiophene)-2carboxylate-2-6-diyl)] (PTB7-Th) as a donor material, ITBR-based OSCs exhibit a PCE as high as $7.49 \%$ with a high $V_{\mathrm{OC}}$ of $1.02 \mathrm{~V}$ as well as a low energy loss of $0.59 \mathrm{eV}$.
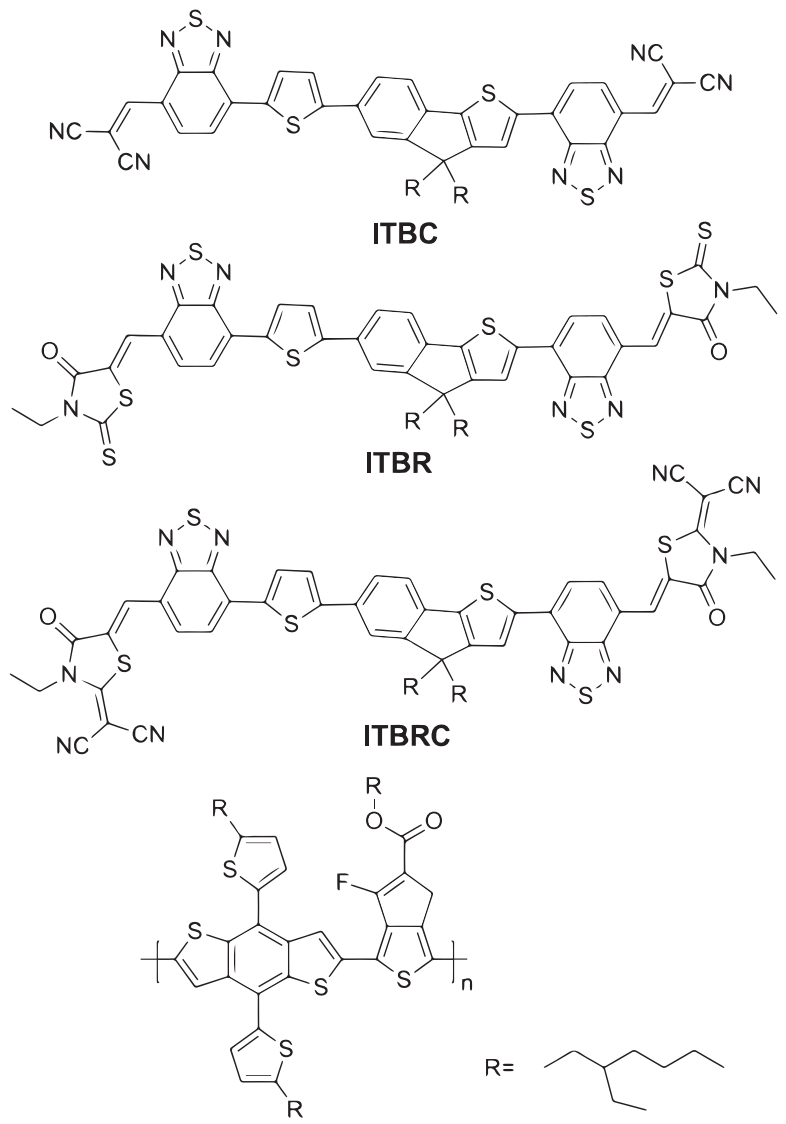

PTB7-Th

Chart 1 Molecular structures of ITBC, ITBR, ITBRC and PTB7-Th.

\section{EXPERIMENTAL SECTION}

\section{Materials}

Reagents were purchased from Adamas beta Ltd. and J\&K Chemical Ltd., and used without further purification unless otherwise stated. Compound IT-Sn was prepared according to the work we published previously [35]. 2-((7Bromobenzo[c] [1,2,5] thiadiazol-4-yl)methylene)malononitrile (1), 7-bromobenzo[c][1,2,5]thiadiazole-4-carbaldehyde (2), 3-ethylrhodanine (4) and 2-(1,1dicyanomethylene)-3-ethylrhodanine (5) were obtained from TCI Ltd. PTB7-Th was purchased from 1-material Inc. Zinc acetate dehydrate (99.9\%), 2-methoxyethanol (99.8\%), and ethanolamine (99.5\%) were purchased from Sigma-aldrich Inc. $\mathrm{MoO}_{3}(99.9 \%)$ was purchased from Alfa Aesar Inc. Column chromatography was conducted with silica gel 60 (400 mesh).

\section{General methods}

${ }^{1} \mathrm{H}$ nuclear magnetic resonance (NMR) and ${ }^{13} \mathrm{C}$ NMR spectra were recorded by using a Bruker AVANCE-III spectrometer. The mass spectra (MS) (MALDI-TOF) were tested on Thermo Fisher Scientific LTQ FT Ultra mass spectrometer. Absorption spectra were acquired using a Perkin-Elmer Lambda 365 UV-vis spectrometer. Cyclic voltammetry (CV) measurements were recorded in an anhydrous and nitrogen-saturated tetrabutylammonium hexafluorophosphate solution $\left(\mathrm{Bu}_{4} \mathrm{NPF}_{6}, 0.1 \mathrm{~mol} \mathrm{~L}^{-1}\right.$ in acetonitrile) at a scan rate of $100 \mathrm{mV} \mathrm{s}^{-1}$, using a Pt disk coated with the acceptor film, $\mathrm{Pt}$ wire, and $\mathrm{Ag} / \mathrm{Ag}^{+}(0.01$ mol L${ }^{-1} \mathrm{AgNO}_{3}$ in anhydrous acetonitrile) as the working electrode, counter electrode and reference electrode, respectively. Under these conditions, the onset oxidation potential $\left(E_{1 / 2}{ }^{\mathrm{ox}}\right)$ of ferrocene was $-0.02 \mathrm{~V}$ versus $\mathrm{Ag} / \mathrm{Ag}^{+}$. Thermogravimetric analysis (TGA) was carried out on a Netzsch STA $449 \mathrm{C}$ instrument at a heating rate of $10^{\circ} \mathrm{C}$ $\mathrm{min}^{-1}$ under nitrogen flow. The $\mathrm{X}$-ray radiation diffraction (XRD) data were recorded on a Bruker D8 Advance diffractometer $\left(\mathrm{Cu} \mathrm{Ka} \alpha_{1}\right.$ irradiation, $\left.\lambda=1.5406 \AA\right)$ set in the grazing incidence mode $\left(\omega=1^{\circ}, 2 \theta\right.$ varied from $5^{\circ}$ to $\left.55^{\circ}\right)$. Solar cell characterization was performed under AM 1.5G irradiation $\left(100 \mathrm{~mW} \mathrm{~cm}^{-2}\right)$ from an Oriel Sol3A simulator (Newport) with a NREL certified silicon reference cell. After a simple encapsulation by epoxy kits (general purpose, Sigma Aldrich) in the glove-box, the OSCs were illuminated through their indium tin oxide (ITO) sides. Current density-voltage $(J-V)$ curves were tested in air by a Keithley 2440 source measurement unit. External quantum efficiency (EQE) spectra were measured on a Newport EQE measuring system. The film thickness data was 
measured by profilometer (Bruker, Dektak XT). Atom force microscopy (AFM) was conducted in the tapping mode with a Bruker Nanoscale V station.

\section{Synthesis}

The synthetic routes to the target acceptor molecules (ITBC, ITBR and ITBRC) are presented in Scheme 1.

\section{Synthesis of ITBC}

Compound IT-Sn (804 mg, $1 \mathrm{mmol})$ and compound 1 $(0.87 \mathrm{~g}, 3 \mathrm{mmol})$ were dissolved in $25 \mathrm{~mL}$ of toluene, and the solution was degassed by bubbling with nitrogen for 30 $\mathrm{min}$, then $58 \mathrm{mg}$ of $\mathrm{Pd}\left(\mathrm{PPh}_{3}\right)_{4}$ was added into the solution. The mixture was degassed again by bubbling with nitrogen for $15 \mathrm{~min}$. The reaction solution was heated to reflux for $24 \mathrm{~h}$. After removal of the solvent, the crude product was purified through a silica gel column with petroleum ether/ $\mathrm{CH}_{2} \mathrm{Cl}_{2}$ (2:1) to give compound ITBC as a dark-red solid (386 mg, 43\%). ${ }^{1} \mathrm{H}$ NMR $\left(\mathrm{CDCl}_{3}, 400 \mathrm{MHz}, \delta / \mathrm{ppm}\right): 8.84-$ $8.81(\mathrm{~m}, 4 \mathrm{H}), 8.42-8.38(\mathrm{~m}, 2 \mathrm{H}), 8.09-8.05(\mathrm{~m}, 2 \mathrm{H}), 7.78-$ $7.73(\mathrm{~m}, 2 \mathrm{H}), 7.63-7.57(\mathrm{~m}, 2 \mathrm{H}), 2.18-2.07(\mathrm{~m}, 4 \mathrm{H}), 1.04-$ $0.87(\mathrm{~m}, 18 \mathrm{H}), 0.74-0.60(\mathrm{~m}, 12 \mathrm{H}) ;{ }^{13} \mathrm{C}$ NMR $(100 \mathrm{MHz}$, $\left.\mathrm{CDCl}_{3}, \delta / \mathrm{ppm}\right): 157.62,155.18,154.55,154.44,152.24$, $152.16,151.15,151.08,150.23,147.01,141.16,138.32$, $137.49,134.13,133.14,132.37,131.55,130.83,130.77$, $126.52,126.34,125.58,124.86,123.94,123.90,123.47$, $121.55,121.23,120.38,114.13,114.00,113.37,113.25$, $82.07,81.57,77.36,77.05,76.73,54.67,43.62,35.23,35.20$, $34.25,34.00,29.72,28.51,28.33,27.53,27.34,22.77,14.06$, 14.04, 10.75, 10.56; high resolution MS (MALDI-TOF, $m /$ $z$ ): ca. for $\mathrm{C}_{51} \mathrm{H}_{46} \mathrm{~N}_{8} \mathrm{~S}_{4}:[\mathrm{M}+\mathrm{H}]^{+}$899.2801; found: 899.2791. Elemental analysis: ca. for $\mathrm{C}_{51} \mathrm{H}_{46} \mathrm{~N}_{8} \mathrm{~S}_{4}: \mathrm{C}, 68.12 ; \mathrm{H}, 5.16 ; \mathrm{N}$, 12.46; found: $\mathrm{C}, 68.47 ; \mathrm{H}, 5.22 ; \mathrm{N}, 12.35$.

\section{Synthesis of compound 3}

The preparative procedure was the same as that used for compound ITBC. Quantities: compound IT-Sn (1.37 g,
$1.7 \mathrm{mmol})$, compound 2 (1.23 g, $5.1 \mathrm{mmol}), \mathrm{Pd}\left(\mathrm{PPh}_{3}\right)_{4}(85$ $\mathrm{mg}$ ), toluene $(50 \mathrm{~mL})$. Compound 3 was obtained as a red solid (1.04 g, 76\%). ${ }^{1} \mathrm{H}$ NMR $\left(\mathrm{CDCl}_{3}, 400 \mathrm{MHz}, \delta / \mathrm{ppm}\right)$ : $10.76(\mathrm{~d}, J=5.2 \mathrm{~Hz}, 2 \mathrm{H}), 8.39-8.36(\mathrm{~m}, 2 \mathrm{H}), 8.30-8.27(\mathrm{~m}$, $2 \mathrm{H}), 8.09-8.05(\mathrm{~m}, 2 \mathrm{H}), 7.76-7.72(\mathrm{~m}, 2 \mathrm{H}), 7.60-7.54(\mathrm{~m}$, $2 \mathrm{H}), 2.15-2.07(\mathrm{~m}, 4 \mathrm{H}), 1.05-0.88(\mathrm{~m}, 18 \mathrm{H}), 0.74-0.60(\mathrm{~m}$, $12 \mathrm{H}$ ); MS (MALDI-TOF, $m / z$ ): ca. for $\mathrm{C}_{45} \mathrm{H}_{46} \mathrm{~N}_{4} \mathrm{O}_{2} \mathrm{~S}_{4}:\left[\mathrm{M}^{+}\right]$ 802.2; found: 802.2 .

\section{Synthesis of ITBR}

Compound 3 (300 mg, $0.37 \mathrm{mmol}$ ), compound 4 (238 mg, $1.48 \mathrm{mmol}$ ), $0.4 \mathrm{~mL}$ of dry pyridine and $25 \mathrm{~mL}$ of $\mathrm{CHCl}_{3}$ were added to a $50-\mathrm{mL}$ flame-dried round-bottom flask. After flushed with $\mathrm{N}_{2}$ for $30 \mathrm{~min}$, the reaction solution was heated to reflux for $24 \mathrm{~h}$. Upon cooling to room temperature, the mixture was precipitated from methanol and filtered. The crude product was purified through a silica gel column with petroleum ether/ $\mathrm{CH}_{2} \mathrm{Cl}_{2}(2: 1)$ to give compound ITBR as a dark-red solid $(207 \mathrm{mg}, 51 \%) .{ }^{1} \mathrm{H}$ NMR $\left(\mathrm{CDCl}_{3}, 400 \mathrm{MHz}, \delta / \mathrm{ppm}\right): 8.55$ (s, 2H), 8.33-8.29 (m, 2H), 8.04-8.00 (m, 2H), 7.77-7.72 (m, 4H), 7.58-7.53 (m, 2H), 4.28 (q, J= 7.2 Hz, 4H), 2.16-2.06 (m, 4H), 1.36 (t, $J=7.2 \mathrm{~Hz}, 6 \mathrm{H}), 1.06-0.87(\mathrm{~m}, 18 \mathrm{H}), 0.75-0.60(\mathrm{~m}$, $12 \mathrm{H}) ;{ }^{13} \mathrm{C}$ NMR $\left(100 \mathrm{MHz}, \mathrm{CDCl}_{3}, \delta / \mathrm{ppm}\right): 192.98,167.53$, $157.12,154.82,154.52,151.76,148.34,144.89,141.38$, $138.27,137.75,131.24,131.15,130.74,129.38,127.14$, $124.97,124.70,124.53,124.28,124.01,121.09,119.89$, $113.02,77.35,77.24,77.03,76.71,54.56,43.63,39.96$, $35.18,34.24,34.02,31.95,29.72,29.39,28.52,28.34,27.51$, 27.32, 22.82, 14.08, 12.35, 10.76, 10.55; high resolution MS (MALDI-TOF, $m / z$ ): ca. for $\mathrm{C}_{55} \mathrm{H}_{56} \mathrm{~N}_{6} \mathrm{O}_{2} \mathrm{~S}_{8}: \quad[\mathrm{M}+\mathrm{H}]^{+}$ 1089.2303; found: 1089.2301. Elemental analysis: ca. for $\mathrm{C}_{55} \mathrm{H}_{56} \mathrm{~N}_{6} \mathrm{O}_{2} \mathrm{~S}_{8}: \mathrm{C}, 60.63 ; \mathrm{H}, 5.18 ; \mathrm{N}, 7.71$; found: C, 60.41; $\mathrm{H}, 5.05 ; \mathrm{N}, 7.57$.

\section{Synthesis of ITBRC}

The preparative procedure was the same as that used for

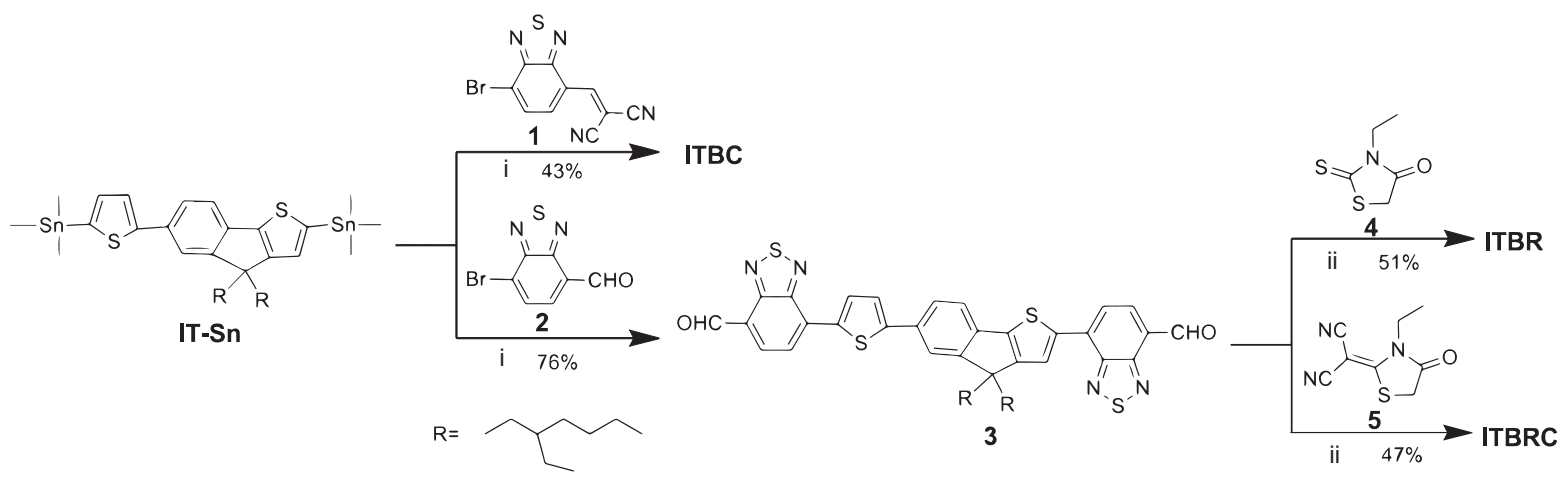

Scheme 1 Synthesis of ITBC, ITBR and ITBRC: i) $\mathrm{Pd}\left(\mathrm{PPh}_{3}\right)_{4}$, toluene, reflux, $24 \mathrm{~h}$; ii) pyridine, $\mathrm{CHCl}_{3}$, reflux, $24 \mathrm{~h}$. 
compound ITBR. Quantities: compound 3 (300 mg, 0.37 $\mathrm{mmol}$ ), compound 5 (286 $\mathrm{mg}, 1.48 \mathrm{mmol})$, pyridine (0.4 $\mathrm{mL}), \mathrm{CHCl}_{3}(25 \mathrm{~mL})$. The product was obtained as a darkred solid (200 mg, 47\%). ${ }^{1} \mathrm{H}$ NMR $\left(\mathrm{CDCl}_{3}, 400 \mathrm{MHz}, \delta /\right.$ ppm): 8.65 (s, $2 \mathrm{H}), 8.37-8.33(\mathrm{~m}, 2 \mathrm{H}), 8.06-8.02(\mathrm{~m}, 2 \mathrm{H})$, 7.86-7.84 (m, 2H), 7.75-7.72 (m, 2H), 7.59-7.54 (m, 2H), $4.41(\mathrm{q}, J=7.2 \mathrm{~Hz}, 4 \mathrm{H}), 2.19-2.06(\mathrm{~m}, 4 \mathrm{H}), 1.48(\mathrm{t}, J=7.2$ $\mathrm{Hz}, 6 \mathrm{H}), 1.06-0.87(\mathrm{~m}, 18 \mathrm{H}), 0.76-0.60(\mathrm{~m}, 12 \mathrm{H}) ;{ }^{13} \mathrm{C}$ NMR (100 MHz, $\left.\mathrm{CDCl}_{3}, \delta / \mathrm{ppm}\right): 166.32,166.26,165.97$, $157.33,154.98,154.03,153.88,151.61,149.01,145.68$, $141.22,138.22,137.47,132.56,131.34,130.99,130.76$, $130.33,125.47,124.43,124.11,123.69,123.45,123.21$, $120.84,120.08,118.24,117.99,113.12,112.15,77.39,77.07$, $76.75,56.15,56.01,54.66,43.59,40.73,35.23,34.27,34.07$, $29.72,28.51,28.35,27.54,27.39,22.86,14.22,14.13,10.79$, 10.61; high resolution MS (MALDI-TOF, $\mathrm{m} / z$ ): ca. for $\mathrm{C}_{61} \mathrm{H}_{56} \mathrm{~N}_{10} \mathrm{O}_{2} \mathrm{~S}_{6}$ : $[\mathrm{M}+\mathrm{H}]^{+}$1153.2985; found: 1153.2987. Elemental analysis: ca. for $\mathrm{C}_{61} \mathrm{H}_{56} \mathrm{~N}_{10} \mathrm{O}_{2} \mathrm{~S}_{6}: \mathrm{C}, 63.51 ; \mathrm{H}, 4.89$; $\mathrm{N}, 12.14$; found: $\mathrm{C}, 63.81 ; \mathrm{H}, 4.94 ; \mathrm{N}, 12.01$.

\section{Device fabrication}

OSCs were fabricated with the structure of $\mathrm{ITO} / \mathrm{ZnO} / \mathrm{ac}-$ tive layer $/ \mathrm{MoO}_{3} / \mathrm{Ag}$. Firstly, the ITO glass was cleaned by ultrasonication sequentially in detergent, water, acetone, and isopropyl alcohol for $30 \mathrm{~min}$ each and then dried overnight in an oven. Then the $\mathrm{ZnO}$ precursor solutions $\left(0.23 \mathrm{~mol} \mathrm{~L}^{-1}\right.$ in 2-methoxyethanol, ethanolamine as a stabilizer) were spin-coated onto the top of the ITOglasses, which were pretreated by $\mathrm{UV}-\mathrm{O}_{3}$ for $15 \mathrm{~min}$. The films were first annealed on a hot plate at $130^{\circ} \mathrm{C}$ for 10 $\min$. Then they were thermally annealed in an oven $\left(200^{\circ}\right.$ C) for an hour. The PTB7-Th:ITBR blend (1:2 by weight) was dissolved in chlorobenzene:diphenyl ether (CB/DPE, $v / v, 98 / 2)$ with a concentration of $25 \mathrm{mg} \mathrm{mL}^{-1}$. The mixture was stirred for a few hours at $50^{\circ} \mathrm{C}$. The solution was spin-coated inside the glovebox. Finally, $10 \mathrm{~nm} \mathrm{MoO}$ and $100 \mathrm{~nm} \mathrm{Ag}$ top electrode were deposited onto the active layer under vacuum. The active area of OSCs was fixed at 6 $\mathrm{mm}^{2}$.

Electron mobility was measured using the space charge limited current model (SCLC), using a diode conguration of ITO/ZnO/active layer/Ca/Al, and taking current-voltage measurements in the range of $0-11 \mathrm{~V}$ in the dark. The SCLC mobilities were estimated by fitting the results to the Mott-Gurney relationship,

$$
J=\frac{9}{8} \varepsilon_{0} \varepsilon_{\mathrm{r}} \mu \frac{V^{2}}{L^{3}},
$$

where $J$ is the current density, $\varepsilon_{0}$ is the permittivity of free space $\left(8.85 \times 10^{-12} \mathrm{~F} \mathrm{~m}^{-1}\right), \varepsilon_{\mathrm{r}}$ is the dielectric constant of the active layer material (assumed to be 3 , which is a typical value for organic semiconductors), $\mu$ is the electron mobility, $V$ is the voltage drop across the device $\left(V=V_{\text {appl }}-\right.$ $V_{\mathrm{bi}}$, where $V_{\mathrm{appl}}$ is the applied voltage to the device, and $V_{\mathrm{bi}}$ is the built-in voltage due to the difference in work function of the two electrodes), and $L$ is the active layer thickness.

\section{RESULTS AND DISCUSSION}

\section{Synthesis and thermal properties}

The first target molecule ITBC was facilely synthesized via a Stille coupling reaction between IT-Sn and $\mathbf{1}$ in 43\% yield. The other two target acceptors were synthesized in two steps, and the key intermediate 3 was prepared in 76\% yield by the coupling reaction between IT-Sn and $\mathbf{2}$. The final Knoevenagel condensation between $\mathbf{3}$ and $\mathbf{4}$ (or 5) in the presence of pyridine afforded ITBR (or ITBRC) in $51 \%$ (or $47 \%$ ) yield. The chemical structures of the target acceptors were characterized by ${ }^{1} \mathrm{H}$ NMR, ${ }^{13} \mathrm{C}$ NMR and $\mathrm{MS}$, and their purity were further confirmed by elemental analysis. ITBC, ITBR and ITBRC exhibit good solubility in common organic solvents such as dichloromethane, chloroform and chlorobenzene at room temperature and can be solution-cast to form smooth films. TGA indicated that all the target molecules possess good thermal stability with a $5 \%$ weight-loss up to $375^{\circ} \mathrm{C}$ which could meet the requirement of device fabrication (Fig. S1).

\section{Optical properties}

The UV-vis absorption spectra of the three acceptors in diluted chloroform solutions and in thin films are shown in Fig. 1. Their absorption data are summarized in Table 1. All molecules showed one high-energy band and one lowenergy band, where the absorption band at $\sim 300-450 \mathrm{~nm}$ is attributed to the $\pi-\pi^{*}$ transition of the conjugated backbone while the low-energy absorption band at $\sim 450$ $850 \mathrm{~nm}$ is originated from the intramolecular chargetransfer (ICT) from the donor core to the terminal acceptors. In solution, ITBRC and ITBC showed a distinct red-shifted absorption in comparison with ITBR, due to the negative inductive effect of the nitrile groups. As shown in Fig. 1b, ITBR, ITBRC and ITBC in thin film show broader absorption in the wavelength region from 460 to $850 \mathrm{~nm}$, and exhibit red-shifts of 51,39 and $49 \mathrm{~nm}$, respectively, in comparison to their corresponding absorption maxima in solution, which can be attributed to the solid-state packing induced conformational change into a more coplanar conjugated molecular backbone. In addition, there are bathochromically shifted absorption 

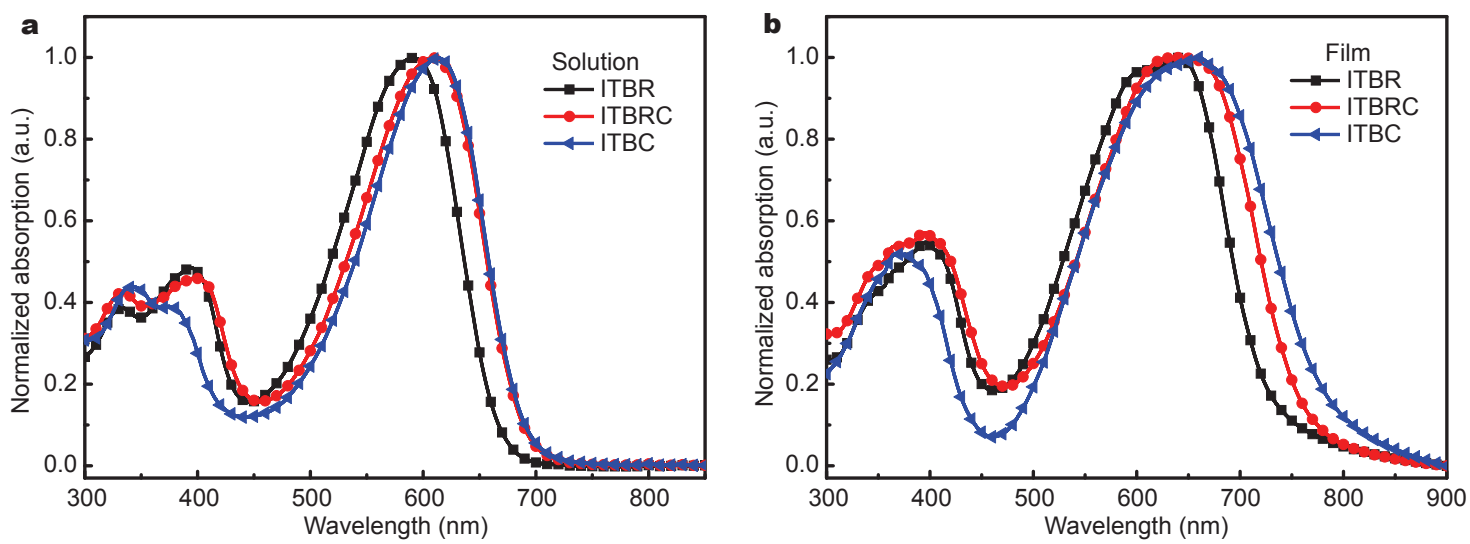

Figure 1 (a) UV-vis absorption spectra of ITBR, ITBRC and ITBC in chloroform and (b) as thin films.

Table 1 Optical and electronic properties of ITBR, ITBRC and ITBC

\begin{tabular}{|c|c|c|c|c|c|c|}
\hline Acceptors & $\lambda_{\max }^{\text {a) }}(\mathrm{nm})$ & $\lambda_{\max }^{\text {b) }}(\mathrm{nm})$ & $E_{\mathrm{g}}^{\text {opt c) }}(\mathrm{eV})$ & HOMO $(\mathrm{eV})$ & LUMO $(\mathrm{eV})$ & $E_{\mathrm{g}}^{\mathrm{cvd})}(\mathrm{eV})$ \\
\hline ITBR & 589 & 640 & 1.71 & -5.55 & -3.71 & 1.84 \\
\hline ITBRC & 609 & 648 & 1.63 & -5.60 & -3.82 & 1.78 \\
\hline ITBC & 612 & 661 & 1.59 & -5.64 & -3.94 & 1.70 \\
\hline
\end{tabular}

a) Absorption maximum in solution. b) Absorption maximum in thin film. c) Optical bandgap calculated from the absorption onset of thin film. d) Electrochemical bandgap obtained from LUMO-HOMO.

peaks going from ITBR $(640 \mathrm{~nm})$ to ITBRC $(648 \mathrm{~nm})$, and to ITBC $(661 \mathrm{~nm})$, due to the increase in the electron withdrawing ability of their terminal units. This trend is consistent with that observed in solution. Optical bandgaps $\left(E_{\mathrm{g}}{ }^{\text {opt }}\right)$ of ITBR, ITBRC and ITBC were estimated to be $1.71,1.63$ and $1.59 \mathrm{eV}$, respectively, according to the absorption edges of the thin films.

\section{Electrochemical properties}

The electrochemical properties of the molecules were investigated by $\mathrm{CV}$. The highest occupied molecular orbital (HOMO) and lowest unoccupied molecular orbital (LUMO) energy levels were estimated from the onset oxidation and reduction potentials, respectively, assuming the absolute energy level of $\mathrm{Fc} / \mathrm{Fc}^{+}$to be $-4.80 \mathrm{eV}$. CV curves are shown in Fig. 2 and the results are listed in Table 1. The HOMO energy levels of ITBR, ITBRC and ITBC were calculated to be $-5.55,-5.60$ and $-5.64 \mathrm{eV}$, while their LUMO energy levels were $-3.71,-3.82$ and $-3.94 \mathrm{eV}$, respectively. The HOMO and LUMO energy levels for the three molecules became deeper going from ITBR to ITBRC, and to ITBC, due to the introduction of strong electron withdrawing groups (malononitrile). Especially, when the malononitrile was used directly as the terminal unit, ITBC exhibited the deepest HOMO and LUMO energy levels. One may find larger shifts in the

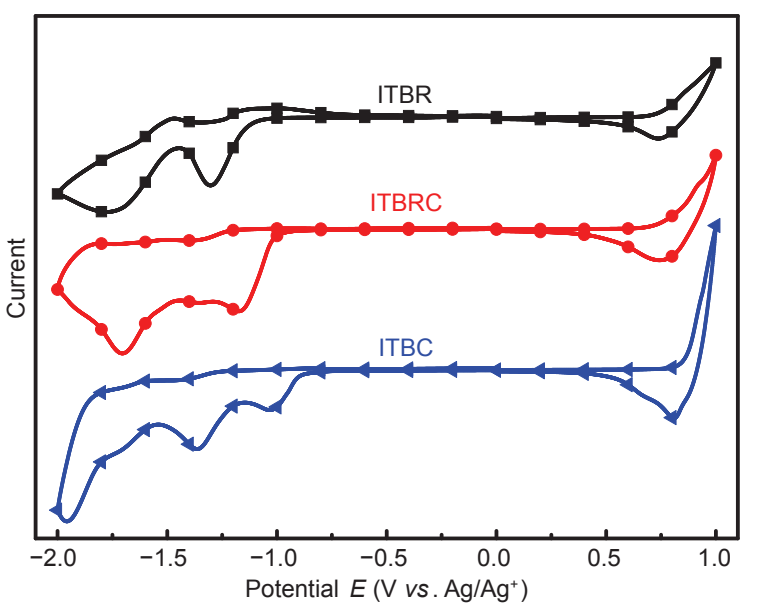

Figure 2 Cyclic voltammogram of the films based on ITBR, ITBRC and ITBC.

LUMO levels of these acceptors in comparison with their HOMO level changes, which is due to the fact that the LUMO and HOMO energy levels of molecules are mainly determined by their electron withdrawing terminal units and electron donating core units, respectively. The electrochemical bandgaps $\left(E_{\mathrm{g}}^{\mathrm{cv}}\right)$ of ITBR, ITBRC and ITBC estimated from the CV data were $1.84,1.78$ and $1.70 \mathrm{eV}$, respectively, following the trend of their optical bandgaps. 


\section{Photovoltaic properties}

The photovoltaic performances of the acceptors were investigated by fabricating solar cells with an inverted configuration of $\mathrm{ITO} / \mathrm{ZnO} /$ active layer $/ \mathrm{MoO}_{3} / \mathrm{Ag}$, and using PTB7-Th as the electron donor material. The optimal fabrication conditions for producing the PTB7-Th:ITBR BHJ layers were obtained by varying the PTB7-Th:ITBR weight ratios, and by tuning the solvent compositions through mixing a trace amount of diphenyl ether (DPE) with chlorobenzene (Tables S1 and S2). The thickness of the active layer is $\sim 90 \mathrm{~nm}$. The best performance devices for the three acceptors were fabricated without thermal annealing at a D/A ratio of 1:2 (wt./wt.), $2 v . \%$ DPE additive in chlorobenzene. The $J-V$ curves for the best devices are shown in Fig. 3a and the device parameters are summarized in Table 2. Without any additive, the best performance OSC based on PTB7-Th:ITBR exhibited a PCE of $5.89 \%$ with a $V_{\mathrm{OC}}$ of $1.03 \mathrm{~V}$, a short circuit current density ( $\left.J_{\mathrm{SC}}\right)$ of $12.29 \mathrm{~mA} \mathrm{~cm}$, and a fill factor (FF) of $46.42 \%$. When $2 \%$ DPE was added, the device based on PTB7-Th:ITBR showed an increased PCE of 7.49\% with the simultaneously enhanced $J_{\mathrm{SC}}$ of $14.46 \mathrm{~mA} \mathrm{~cm}^{-2}$ and $\mathrm{FF}$ of $51.02 \%$. It is worth noting that the high $V_{\mathrm{OC}}$ of $1.02 \mathrm{~V}$ represents one of the highest values among PTB7-Thbased devices and accounts for less than $0.6 \mathrm{eV}$ of energy loss, which is even lower than the empirical suggested minimum photon energy loss for efficient charge generation in OSCs [36]. However, there is still room for improvement of the performance of this new acceptor considering the relatively small FF compared to those of the analog materials with symmetric structures based on IDT [33]. For the OSCs based on ITBC and ITBRC, the $V_{\mathrm{OC}}$ decreased to $0.79 \mathrm{~V}$ and $0.90 \mathrm{~V}$, respectively, due to their deeper LUMO energy levels. The PTB7-Th:ITBCbased OSCs exhibited a best PCE of $6.27 \%$ with a $V_{\text {OC }}$ of $0.79 \mathrm{~V}$, a $J_{\mathrm{SC}}$ of $13.34 \mathrm{~mA} \mathrm{~cm}^{-2}$, and a FF of $59.49 \%$, while ITBRC displayed a lower PCE of $4.26 \%$ with a $V_{\text {OC }}$ of 0.91 $\mathrm{V}$, a $J_{\mathrm{SC}}$ of $9.21 \mathrm{~mA} \mathrm{~cm}^{-2}$, and a FF of $51.04 \%$.

To verify the accuracy of the PCE measurements, external quantum efficiencies (EQEs) of the OSCs based on the three acceptors with DPE were measured and the EQE spectra are depicted in Fig. 3b. The OSCs based on these three acceptors show broad photoresponse in the range from 300 to $850 \mathrm{~nm}$. The maximum EQE values of ITBR, ITBC and ITBRC-based devices are 69.6\%, 59.6\%, and $48.5 \%$, respectively. The ITBR-based device exhibited the highest average $\mathrm{EQE}$ values among the three acceptors. The $J_{\text {SC }}$ values of ITBR, ITBC and ITBRC-based devices calculated from the integration of $\mathrm{EQE}$ spectra with the AM 1.5G reference spectrum are 13.89, 12.90 and $9.23 \mathrm{~mA}$ $\mathrm{cm}^{-2}$, respectively, which are in good agreement with the $J_{\text {SC }}$ values obtained from the $J-V$ measurements.
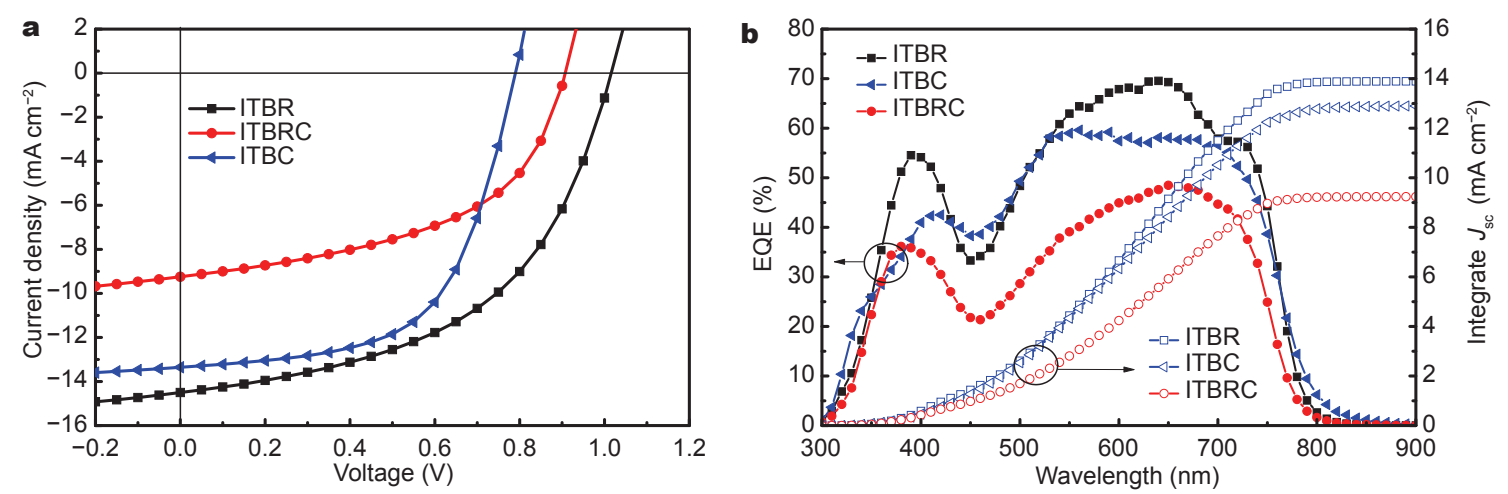

Figure $3 \mathrm{~J}$-V curves (a) and EQE spectra (b) for OSCs based on PTB7-Th/acceptor with 2\% DPE.

Table 2 Device performances of OSCs based on PTB7-Th:acceptor

\begin{tabular}{ccccc}
\hline Acceptors & $V_{\mathrm{OC}}(\mathrm{V})$ & $J_{\text {SC }}\left(\mathrm{mA} \mathrm{cm}^{-2}\right)$ & FF (\%) & PCE $^{\text {a) }}(\%)$ \\
\hline ITBR & 1.03 & 12.29 & 46.42 & $5.89(5.74 \pm 0.11)$ \\
ITBR $^{\text {b) }}$ & 1.02 & 14.46 & 51.02 & $7.49(7.34 \pm 0.12)$ \\
ITBC $^{\text {b) }}$ & 0.79 & 12.30 & 58.58 & $5.70(5.60 \pm 0.07)$ \\
ITBC $^{\text {b }}$ & 0.79 & 13.34 & 59.49 & $6.27(6.05 \pm 0.15)$ \\
ITBRC $^{\text {ITBRC }}{ }^{\text {b) }}$ & 0.91 & 9.89 & 46.15 & $4.15(4.07 \pm 0.07)$ \\
\end{tabular}

a) Average PCEs and standard deviations in the brackets were obtained from 8 cells. b) With $2 \%$ DPE additive. 
Film morphology and charge carrier mobilities

AFM was performed to investigate the surface morphology of these three active layers. The AFM height images for the three active layers with or without DPE are shown in Fig. 4. It can be found that all films present similar smooth surface with a root-mean-square (RMS or $R_{\mathrm{q}}$ ) roughness of $1.63 \mathrm{~nm}$ for PTB7-Th:ITBR, $1.66 \mathrm{~nm}$ for PTB7-Th:ITBC, and $1.47 \mathrm{~nm}$ PTB7-Th:ITBRC, respectively, when no DPE was added. However, after the addition of DPE, the blend film based on ITBR became smoother with a decreased RMS roughness of $1.25 \mathrm{~nm}$, while the RMS roughnesses for ITBC and ITBRC-based films increased to $2.01 \mathrm{~nm}$ and $3.07 \mathrm{~nm}$, respectively. The greatly reduced RMS roughness for the PTB7-Th:ITBR blend with DPE additive may explain the higher percentage of PCE enhancement for the OSCs with DPE. However, the investigation on detailed morphology-performance relationships is still needed in our ongoing research. Besides, XRD experiments were used to study the crystallinity of the pure acceptors. As shown in Fig. S2, the films of the three acceptors show no obvious XRD peaks indicating their amorphous nature.

The charge carrier mobilities of PTB7-Th:ITBR, PTB7Th:ITBRC and PTB7-Th:ITBC devices were evaluated by using the SCLC model for electron-only devices with the device structure of ITO/ZnO/active layer/Ca/Al (Fig. S3).
The electron mobilities of ITBR, ITBC and ITBRC-based devices are $1.51 \times 10^{-5}, 2.89 \times 10^{-5}$, and $1.33 \times 10^{-5} \mathrm{~cm}^{2} \mathrm{~V}^{-1} \mathrm{~s}^{-1}$, respectively. The device based on ITBC demonstrated the highest electron mobility among the three acceptors, which explained its improved FF values for the corresponding devices. At the same time, the hole mobility of the donor polymer was evaluated by using the SCLC model for hole-only devices with a device structure of ITO/PEDOT:PSS/PTB7-Th:ITBC/ $/ \mathrm{MoO}_{3} / \mathrm{Au}$ (Fig. S4). The hole mobility was calculated to be $2.61 \times 10^{-5} \mathrm{~cm}^{2} \mathrm{~V}^{-1}$ $\mathrm{s}^{-1}$, which indicated balanced hole and electron mobilities for the ITBC-based devices.

\section{Solar cell device stability}

Besides high efficiency, long-term device stability is also important for OSCs. Therefore, we further examined the shelf-life stability of these non-fullerene OSCs. The devices were encapsulated with epoxy and stored in air. The device stability of OSCs based on ITBR as a function of storage time under ambient conditions is shown in Fig. 5. The device exhibits good stability, and its PCEs can maintain at approximately over $98 \%$ of its original values after storage in air for 50 days. The $V_{\mathrm{OC}}$ of the device over this period remains relatively constant with slightly decreased $J_{\mathrm{SC}}$, leading to normalized PCEs with a small degradation. Interestingly, FF exhibits even a little increase after one
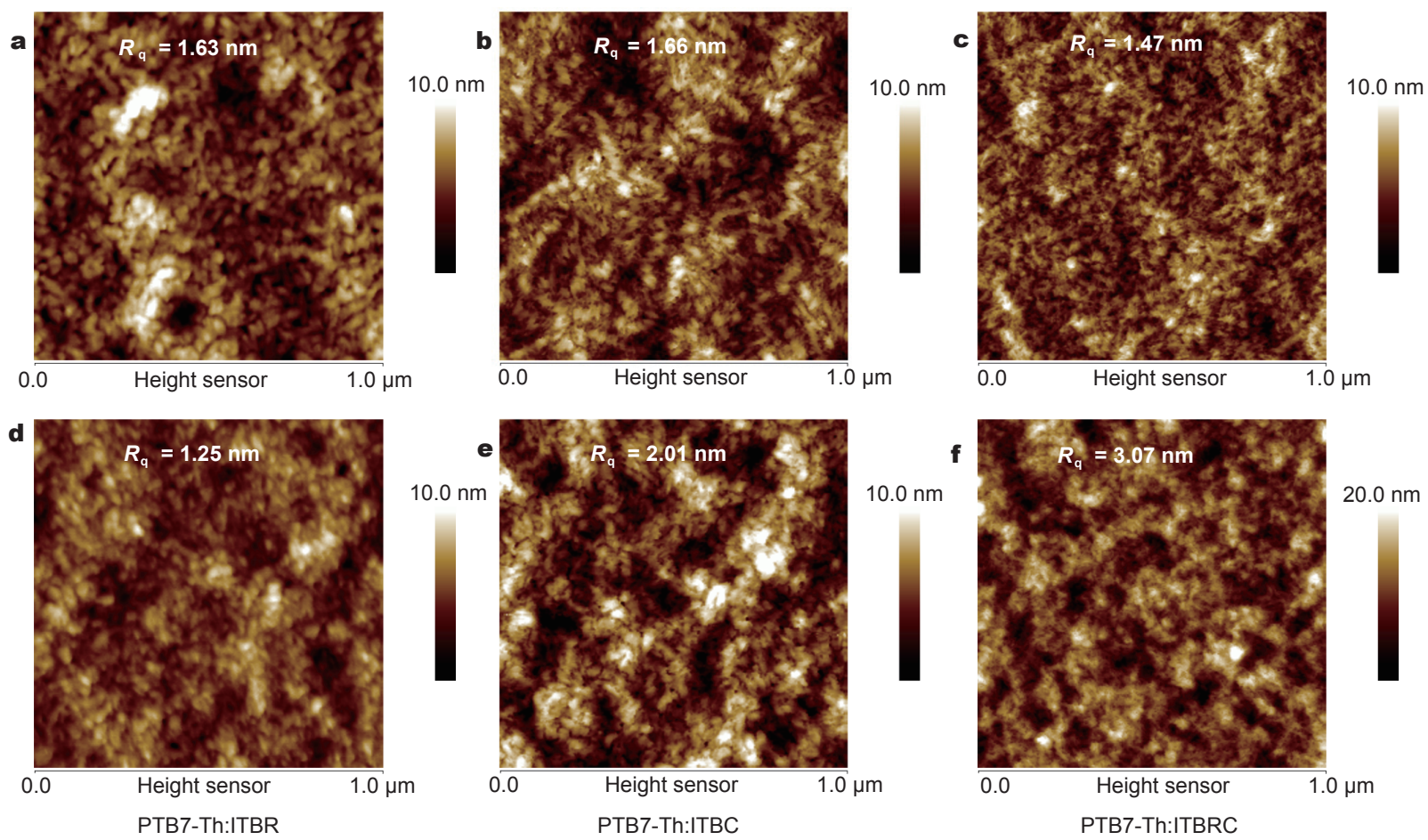

Figure 4 Tapping mode AFM height images of blend films without additives (a-c), and with DPE (d-f). 

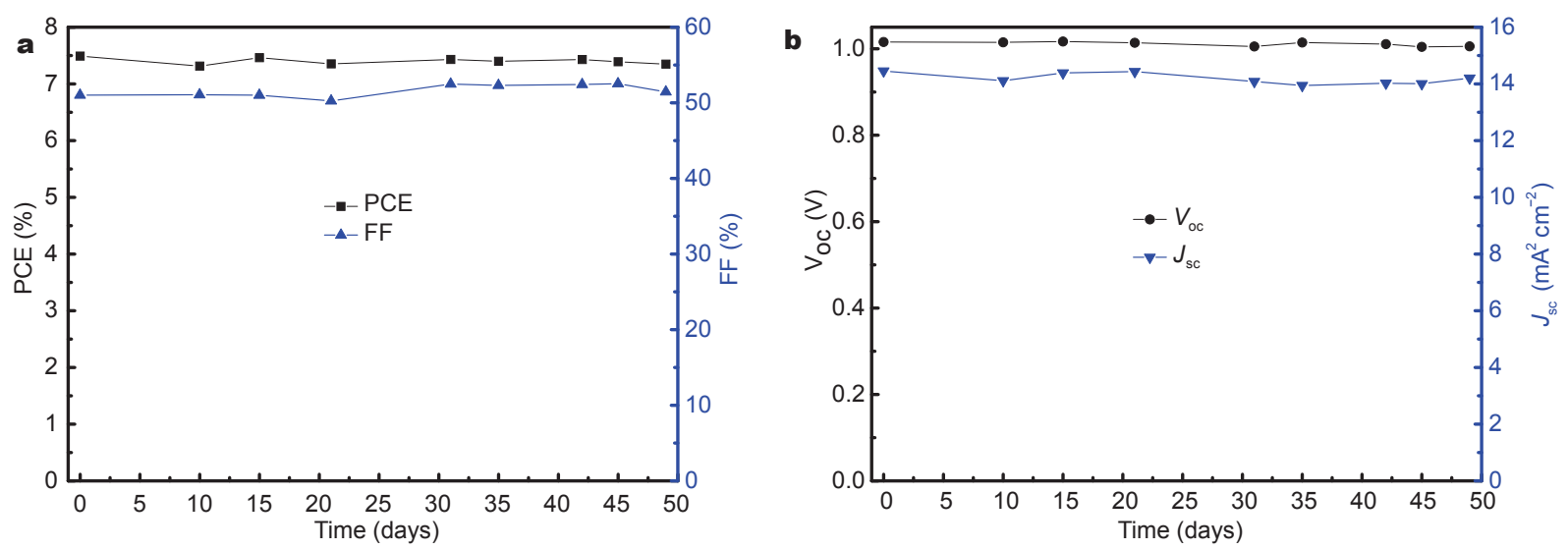

Figure 5 Photovoltaic parameters of the inverted solar cells based on PTB7-Th:ITBR are plotted as functions of storage time: (a) PCE and FF versus storage time and (b) $V_{\mathrm{OC}}$ and $J_{\mathrm{SC}}$ versus storage time.

month.

\section{CONCLUSIONS}

In summary, three non-fullerene acceptors based on an asymmetric donor unit of indenothiophene were designed, synthesized and characterized. Their bandgaps and energy levels can be easily tuned by varying the electron withdrawing ability of the terminal groups which have significant effects on the performance of OSCs. The best performance OSCs based on these acceptors achieved a high PCE up to $7.49 \%$ and a high $V_{\mathrm{OC}}$ of $1.02 \mathrm{~V}$ together with a low energy loss of $0.59 \mathrm{eV}$, all of which indicate that the asymmetric indenothiophene-cored small molecules can be a new type of non-fullerene acceptors for high performance OSCs.

Received 2 May 2017; accepted 1 June 2017;

published online 17 July 2017

1 Sariciftci NS, Smilowitz L, Heeger AJ, et al. Photoinduced electron transfer from a conducting polymer to buckminsterfullerene. Science, 1992, 258: 1474-1476

2 Cheng YJ, Yang SH, Hsu CS. Synthesis of conjugated polymers for organic solar cell applications. Chem Rev, 2009, 109: 5868-5923

$3 \mathrm{He} \mathrm{Y,} \mathrm{Li} \mathrm{Y.} \mathrm{Fullerene} \mathrm{derivative} \mathrm{acceptors} \mathrm{for} \mathrm{high} \mathrm{performance}$ polymer solar cells. Phys Chem Chem Phys, 2011, 13: 1970-1983

4 Nielsen CB, Holliday S, Chen HY, et al. Non-fullerene electron acceptors for use in organic solar cells. Acc Chem Res, 2015, 48: 2803-2812

5 Eftaiha AF, Sun JP, Hill IG, et al. Recent advances of non-fullerene, small molecular acceptors for solution processed bulk heterojunction solar cells. J Mater Chem A, 2014, 2: 1201-1213

6 Chen W, Zhang Q. Recent progress in non-fullerene small molecule acceptors in organic solar cells (OSCs). J Mater Chem C, 2017, 5: $1275-1302$

7 Lin Y, Zhan X. Non-fullerene acceptors for organic photovoltaics: an emerging horizon. Mater Horiz, 2014, 1: 470-488

8 Zhan C, Zhang X, Yao J. New advances in non-fullerene acceptor based organic solar cells. RSC Adv, 2015, 5: 93002-93026

9 Zhou Y, Kurosawa T, Ma W, et al. High performance all-polymer solar cell via polymer side-chain engineering. Adv Mater, 2014, 26: 3767-3772

10 Zhou E, Cong J, Wei Q, et al. All-polymer solar cells from perylene diimide based copolymers: material design and phase separation control. Angew Chem Int Ed, 2011, 50: 2799-2803

11 Zhang X, Zhan C, Yao J. Non-fullerene organic solar cells with $6.1 \%$ efficiency through fine-tuning parameters of the film-forming process. Chem Mater, 2015, 27: 166-173

12 Hartnett PE, Timalsina A, Matte HSSR, et al. Slip-stacked perylenediimides as an alternative strategy for high efficiency nonfullerene acceptors in organic photovoltaics. J Am Chem Soc, 2014, 136: $16345-16356$

13 Liu J, Chen S, Qian D, et al. Fast charge separation in a nonfullerene organic solar cell with a small driving force. Nat Energ, 2016, 1: 16089

$14 \mathrm{Li} \mathrm{H}$, Hwang YJ, Courtright BAE, et al. Fine-tuning the 3D structure of nonfullerene electron acceptors toward high-performance polymer solar cells. Adv Mater, 2015, 27: 3266-3272

15 Li Z, Xu X, Zhang W, et al. High performance all-polymer solar cells by synergistic effects of fine-tuned crystallinity and solvent annealing. J Am Chem Soc, 2016, 138: 10935-10944

16 Yan $\mathrm{H}$, Chen Z, Zheng Y, et al. A high-mobility electron-transporting polymer for printed transistors. Nature, 2009, 457: 679-686

17 Chen W, Nakano M, Kim JH, et al. Naphtho[2,3-b]thiophene diimide (NTI): a mono-functionalisable core-extended naphthalene diimide for electron-deficient architectures. J Mater Chem C, 2016, 4: 8879-8883

18 Fang Y, Pandey AK, Nardes AM, et al. A narrow optical gap small molecule acceptor for organic solar cells. Adv Energ Mater, 2013, 3: $54-59$

19 Schwenn PE, Gui K, Nardes AM, et al. A small molecule nonfullerene electron acceptor for organic solar cells. Adv Energ Mater, 2011, 1: 73-81

20 Zhou T, Jia T, Kang B, et al. Nitrile-substituted QA derivatives: new acceptor materials for solution-processable organic bulk heterojunction solar cells. Adv Energ Mater, 2011, 1: 431-439 
21 Li S, Liu W, Shi M, et al. A spirobifluorene and diketopyrrolopyrrole moieties based non-fullerene acceptor for efficient and thermally stable polymer solar cells with high open-circuit voltage. Energ Environ Sci, 2016, 9: 604-610

22 Sonar P, Ng GM, Lin TT, et al. Solution processable low bandgap diketopyrrolopyrrole (DPP) based derivatives: novel acceptors for organic solar cells. J Mater Chem, 2010, 20: 3626-3636

23 Lin Y, Wang H, Li Y, et al. A star-shaped electron acceptor based on 5,5'-bibenzothiadiazole for solution processed solar cells. J Mater Chem A, 2013, 1: 14627-14632

24 Holliday S, Ashraf RS, Nielsen CB, et al. A rhodanine flanked nonfullerene acceptor for solution-processed organic photovoltaics. J Am Chem Soc, 2015, 137: 898-904

$25 \mathrm{Ni}$ W, Wan X, Li M, et al. A-D-A small molecules for solutionprocessed organic photovoltaic cells. Chem Commun, 2015, 51: 4936-4950

26 Li S, Ye L, Zhao W, et al. Energy-level modulation of small-molecule electron acceptors to achieve over $12 \%$ efficiency in polymer solar cells. Adv Mater, 2016, 28: 9423-9429

27 Lin Y, Wang J, Zhang ZG, et al. An electron acceptor challenging fullerenes for efficient polymer solar cells. Adv Mater, 2015, 27: 1170-1174

28 Qiu N, Zhang H, Wan X, et al. A new nonfullerene electron acceptor with a ladder type backbone for high-performance organic solar cells. Adv Mater, 2017, 29: 1604964

29 Lin Y, Zhang ZG, Bai H, et al. High-performance fullerene-free polymer solar cells with 6.31\% efficiency. Energ Environ Sci, 2015, 8: $610-616$

30 Yang Y, Zhang ZG, Bin H, et al. Side-chain isomerization on an ntype organic semiconductor ITIC acceptor makes $11.77 \%$ high efficiency polymer solar cells. J Am Chem Soc, 2016, 138: 1501115018

31 Wu Y, Bai H, Wang Z, et al. A planar electron acceptor for efficient polymer solar cells. Energ Environ Sci, 2015, 8: 3215-3221

32 Zhao W, Zhang S, Hou J. Realizing $11.3 \%$ efficiency in fullerenefree polymer solar cells by device optimization. Sci China Chem,
2016, 59: 1574-1582

33 Holliday S, Ashraf RS, Wadsworth A, et al. High-efficiency and airstable P3HT-based polymer solar cells with a new non-fullerene acceptor. Nat Commun, 2016, 7: 11585

34 Wang $\mathrm{M}$, Wang Z, Ma W, et al. Indenothiophene-based wide bandgap copolymer for polymer fullerene solar cells with 9.01\% efficiency and $1.0 \mathrm{~V}$ open circuit voltage. Adv Electron Mater, 2016, 2: 1600340

35 Wang M, Cai D, Yin Z, et al. Asymmetric-indenothiophene-based copolymers for bulk heterojunction solar cells with $9.14 \%$ efficiency. Adv Mater, 2016, 28: 3359-3365

36 Veldman D, Meskers SCJ, Janssen RAJ. The energy of chargetransfer states in electron donor-acceptor blends: insight into the energy losses in organic solar cells. Adv Funct Mater, 2009, 19: 1939-1948

Acknowledgements This work was financially supported by the National Natural Science Foundation of China (U1605241, 51503209 and 21502194), the Natural Science Foundation of Fujian Province (2015H0050), the Key Research Program of Frontier Sciences, Chinese Academy of Sciences (QYZDB-SSW-SLH032), and the Strategic Priority Research Program of the Chinese Academy of Sciences (XDB20000000).

Author contributions Tang $\mathrm{C}$ and Chen SC contributed equally to this work. Tang $\mathrm{C}$ and Zheng $\mathrm{Q}$ proposed and designed the project. Tang C synthesized the materials, and Chen SC fabricated and characterized the devices. Tang C, Chen SC and Zheng Q wrote the paper. Shang Q synthesized the starting materials. All authors contributed to the general discussion.

Conflict of interset The authors declare that they have no conflict of interest.

Supplementary information TGA curves, XRD patterns, SCLC curves and device parameters for the OSCs fabricated at different conditions are available in the online version of the paper. 

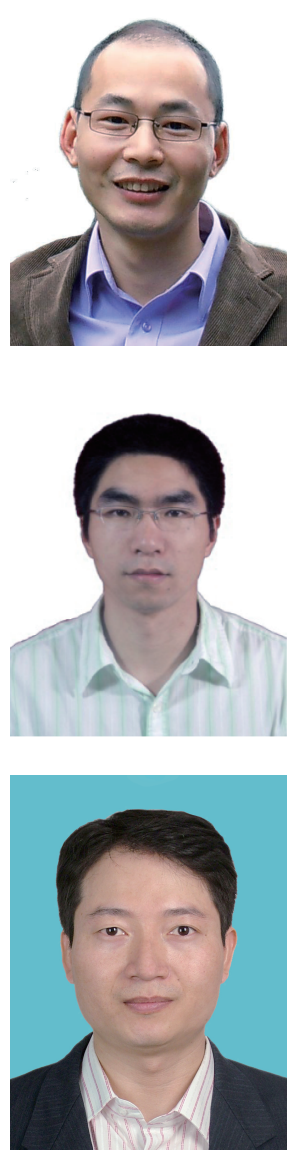

Changquan Tang received his BSc degree from Jiangxi Normal University in 2007 and MSc degree in organic chemistry from Central South University in China in 2010, and then he joined Prof. Qingdong Zheng's group. He is currently pursuing his $\mathrm{PhD}$ in the University of Chinese Academy of Sciences. His research interests focus on the design, synthesis and applications of photon-active materials and organic semiconductor materials.

Shan-Ci Chen received his BSc degree in chemistry from Xiamen University in 2005 and $\mathrm{PhD}$ degree in physical chemistry from Fujian Institute of Research on the Structure of Matter (FJIRSM), Chinese Academy of Sciences in 2010. He is now an associate professor in Prof. Qingdong Zheng's group at FJIRSM, Chinese Academy of Sciences. His interest involves the design, synthesis, and characterizations of materials for various applications including organic field-effect transistors, organic solar cells, etc.

Qingdong Zheng obtained his PhD degree from the State University of New York at Buffalo, USA in 2005. After carrying out his postdoctoral research at Johns Hopkins University, he joined FJIRSM, Chinese Academy of Sciences, and became a professor in 2010. His main interests focus on multifunctional molecular materials and devices and in particular on the fields of semiconducting materials for organic solar cells.

\section{含狮并噻吩的不对称非富勒烯受体材料及其高性能聚合物太阳电池}

汤昌泉 ${ }^{1,2 \dagger}$, 陈善慈 $^{1 \dagger}$, 尚启 ${ }^{1}$, 郑庆东 $^{{ }^{*}}$

摘要 本文设计合成了三个新型含狮并噻吩的 “受体-给体-受体” 型不对称非富勒烯受体材料. 通过使用具有不同吸电子能力的末端基团(如: 二氧乙烯基、3-乙基绕丹宁、2-二氧亚甲基-3-乙基绕丹宁)实现了目标材料的带隙和能级调控. 以这些非富勒烯受体材料与PTB7-Th给体材料 共混制备的倒置聚合物太阳电池, 实现了高达 $7.49 \%$ 的光电转换效率和 1.02 伏的高开路电压以及 0.59 电子伏的低能量损失. 